\title{
MUSCARINE-SENSITIVE VOLTAGE-DEPENDENT POTASSIUM CURRENT IN CULTURED MURINE SPINAL CORD NEURONS
}

\author{
LINDA M. NOWAK* and ROBERT L. MACDONALD** \\ Department of Neurology, The University of Michigan, Ann Arbor, MI (U.S.A.)
}

(Received September 17th, 1982; Revised version received November 23rd, 1982; Accepted November 30th, 1982)

Key words: muscarine cholinergic actions - m-current - spinal cord neurons - cell culture

\begin{abstract}
Muscarine produced membrane depolarization and decreased membrane conductance of mouse spinal cord neurons in dissociated cell culture. When the neurons were voltage clamped, muscarine evoked inward currents which increased with membrane depolarization and decreased with membrane hyperpolarization. However, the muscarine-induced inward currents did not invert at large negative potentials, suggesting that muscarine decreased a voltage-dependent potassium current (m-current) [2]. Using the voltage-jump current-relaxation technique, m-current was demonstrated in spinal cord neurons and shown to be a muscarine-sensitive potassium current.
\end{abstract}

Muscarine produces slow membrane depolarization of vertebrate sympathetic ganglion neurons $[2,15]$ and mammalian central neurons $[6,11,12,16]$ associated with increased input resistance due to a decrease in potassium conductance $\left(\mathrm{g}_{\mathrm{K}}\right)[2$, $6,11,12,15]$. In sympathetic ganglion neurons, muscarinic responses often did not reverse polarity at potentials more negative than the predicted potassium equilibrium potential $\left(E_{\mathbf{K}}\right)$ [3]. Similarly, in voltage-clamp studies of mouse spinal cord neurons in cell culture, muscarine-induced current responses did not have reversal potentials at large negative holding potentials [12]. Recently, Brown and Adams [2] demonstrated a time- and voltage-dependent potassium current in frog sympathetic ganglion neurons which was reduced by muscarine. This potassium current (called m-current) was activated by depolarization and not present at large negative potentials. Thus, it was suggested that the lack of a reversal potential in sympathetic ganglion neurons could be explained by muscarinic reduction of $\mathrm{m}$ current. m-Current has since been demonstrated in mammalian sympathetic

\footnotetext{
* Present address: Laboratoire de Neurobiologie, Ecole Normale Superieure, Paris 75005, France.

** Author for correspondence at: Neuroscience Laboratory Building, 1103 E. Huron, Ann Arbor, MI 48109, U.S.A.
} 
ganglion neurons [5, 8] and hippocampal neurons [1]. In the present studies, we have demonstrated a muscarine-sensitive potassium current similar to m-current and suggest that muscarinic cholinergic responses of mouse spinal cord neurons in cell culture are due, at least in part, to reduction of m-current.

Spinal cords and dorsal root ganglia were removed from 12.5-13.5-day-old fetal mice and mechanically dissociated. Neurons were grown in cell culture for $4-8$ weeks prior to study as previously described [13]. Recordings were made on the modified, heated $\left(30^{\circ} \mathrm{C}\right)$ stage of an inverted phase-contrast microscope. Intracellular recordings were made using either $4 \mathrm{M} \mathrm{KAc}$ - or $3 \mathrm{M} \mathrm{KCl}$-filled glass micropipettes (20-35 $\mathrm{M} \Omega$ ). Muscarine-induced transmembrane currents and voltage-jump-induced current relaxations were recorded from the somata of spinal cord neurons using a single-electrode voltage clamp (Dagan 8100 ) technique [7] ( $3 \mathrm{kHz}$ switching frequency; 50-50 duty cycle). Cells were penetrated with beveled, $3 \mathrm{M} \mathrm{KCl-filled} \mathrm{glass}$ micropipettes (10-25 M $\Omega$ ). Micropipette shafts were coated with conductive paint. A polystyrene compound (Q-dope; GC Electronics) was then applied to within 200 $\mu \mathrm{m}$ of the micropipette tip. Adequacy of the voltage clamp was verified by inserting a second independent voltage monitoring pipette in some neurons during voltage clamp recordings.

Recording medium was a Tris-HCl-buffered ( $\mathrm{pH} 7.2-7.4$ ) balanced saline (TBS) (305-320 mOsm) containing (in mM): $137.5 \mathrm{NaCl}, 5.0 \mathrm{KCl}, 5.0 \mathrm{CaCl}_{2}, 0.8 \mathrm{MgCl}_{2}$, 13.0 Tris base and 5.6 glucose. Tetrodotoxin (TTX, $3 \mu \mathrm{M}$ ) was added to the bathing medium used for voltage clamp experiments to eliminate voltage-dependent sodium currents, and tetraethylammonium (TEA, 5 or $10 \mathrm{mM}$ ) was present during some experiments to reduce delayed rectifier potassium currents. When extracellular potassium was increased from 5 to $15 \mathrm{mM}$ or TEA was included, sodium was reduced to maintain osmolarity. DL-Muscarine (Sigma) was applied locally to neuronal somata by pressure ejection from small tipped $(5-10 \mu \mathrm{m})$ glass micropipettes or by diffusion from larger tipped $(20-30 \mu \mathrm{m})$ glass micropipettes brought to within $5 \mu \mathrm{m}$ of the cell membrane.

Muscarine $(1-25 \mu \mathrm{M})$ evoked slow membrane depolarizations and increased the frequency of action potentials in about $70 \%$ (15 of 22 cells) of large spinal cord neurons (Fig. 1A). These cholinergic actions were reversibly antagonized by $1-5 \mu \mathrm{M}$ atropine sulfate. Muscarine-evoked depolarizations were associated with decreases in membrane conductance as shown by the increased voltage responses to brief hyperpolarizing constant current pulses applied to the cells using the single electrode bridge technique (Fig. 1B). During voltage clamp, muscarine evoked inward currents ( 14 cells) (Fig. 1C, lower trace) which were slow in onset ( 0.4 sec latency) and outlasted $1 \mathrm{sec}$ drug applications by $10-30 \mathrm{sec}$. Brief $(500 \mathrm{msec})$ hyperpolarizing voltage-commands (Fig. 1C, upper trace) were employed during voltage clamp recordings to measure conductance changes. Following application of muscarine less current was required to achieve the command voltage, indicating that muscarine decreased membrane conductance. Muscarine-induced inward currents were also 

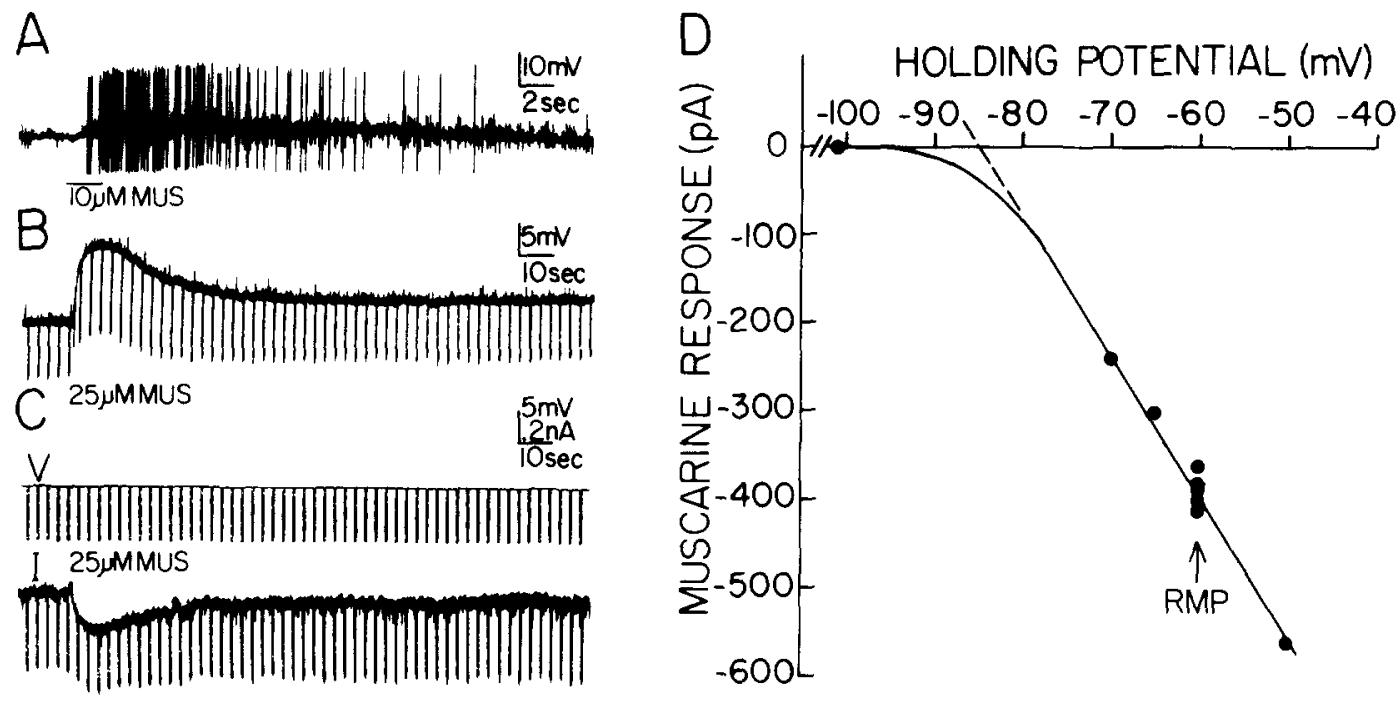

Fig. 1. Muscarine (MUS) decreased a voltage-dependent membrane conductance. A: $10 \mu \mathrm{M}$ MUS (2 sec) evoked slow ( $0.5 \mathrm{sec}$ latency), prolonged, depolarizing responses and produced action potential firing. $\mathrm{Vm}-52.5 \mathrm{mV}, 4 \mathrm{M} \mathrm{KAc}$-filled micropipettes, $2 \mathrm{mM} \mathrm{Ca}^{2+}$-containing TBS. B: $25 \mu \mathrm{M}$ MUS evoked large, reversible depolarizations. The voltage response to $500 \mathrm{msec}$ hyperpolarizing constant current pulses increased during membrane depolarization. Vm was $-49 \mathrm{mV}$. In B, C and D $3 \mathrm{M} \mathrm{KCl}$-filled intracellular micropipettes were used and bathing medium was $3 \mu \mathrm{M}$ TTX-containing TBS. C: MUS-induced slow, inward current responses (lower trace) from neurons which were voltage-clamped at holding potentials less than $\left(V_{H}=-42 \mathrm{mV}\right)$ or equal to $\mathrm{Vm}(-49 \mathrm{mV})$. Current responses (lower trace) to 500 msec hyperpolarizing voltage commands (upper trace) were decreased during MUS-induced inward current. Data in $\mathrm{B}$ and $\mathrm{C}$ are from the same neuron. D: $10 \mu \mathrm{M}$ MUS-induced inward current responses were not linearly related to membrane potential. Vm was $-60 \mathrm{mV}$. At large negative $\mathrm{V}_{\mathrm{H}} \mathrm{s}(-65$ and $-70 \mathrm{mV})$, muscarineinduced inward current decreased, and at less negative $V_{\mathrm{H}} \mathrm{s}(-50 \mathrm{mV})$, muscarine-induced inward current was increased so that an extrapolated reversal potential of $-85 \mathrm{mV}$ was obtained (dashed line). However, at large negative $\mathrm{V}_{\mathrm{H}}$ s (e.g. $-101 \mathrm{mV}$ ), $10 \mu \mathrm{M}$ MUS did not evoke any current response.

recorded using $3 \mathrm{M} \mathrm{KCl-filled} \mathrm{micropipettes} \mathrm{(Fig.} \mathrm{1B,} \mathrm{C).} \mathrm{Since} \mathrm{chloride} \mathrm{equilibrium}$ potential was about $-20 \mathrm{mV}$ during $\mathrm{KCl}$ recording, decreasing chloride conductance $\left(\mathrm{g}_{\mathrm{Cl}}\right)$ should have resulted in outward, not inward, currents. Thus, it was likely that muscarine decreased a $\mathrm{g}_{\mathrm{K}}$ rather than a $\mathrm{g}_{\mathrm{Cl}}$.

Muscarine-induced current responses, however, did not vary linearly with membrane potential, being larger at holding potentials less negative than resting membrane potential $(\mathrm{Vm})$ and smaller at holding potentials more negative than resting potential (Fig. 1D). Muscarine did not evoke responses at holding potentials 20-40 $\mathrm{mV}$ more negative than resting potential (Fig. $1 \mathrm{D}$; see $-101 \mathrm{mV}$ ) in most neurons ( 6 of 7 ). In the one case where muscarine-induced currents reversed polarity at large negative holding potentials, the magnitude of the outward currents was less than predicted from responses measured at less negative potentials. The most likely explanation of these results is that muscarine decreased a voltage-dependent potassium 
current which was activated by membrane depolarization and absent following membrane hyperpolarization, similar to the muscarine-sensitive m-current of frog sympathetic ganglion neurons [2].

We investigated the possibility that m-current was present in mouse spinal cord neurons by using the voltage-jump technique [2]. Membrane holding potential $\left(\mathrm{V}_{\mathrm{H}}\right)$ was decreased from resting membrane potential and held constant. Constant amplitude, negative voltage command steps ( $\mathrm{V}_{\mathrm{C}} ; 500$ or $750 \mathrm{msec}$ ) were applied, and the resulting early currents and relaxation currents were recorded. In the active range of the conductance-voltage relationship of the slow, voltage-dependent potassium current, rapid change of potential resulted in an early current followed by a time-dependent increase or decrease in the total current ( 5 cells) (current relaxation). Data from one neuron are shown in Fig. 2A. A small $V_{C}(-7 m V)$ from holding potential ( $-28 \mathrm{mV}$ ) evoked an initial inward current of $670 \mathrm{pA}$ (Fig. 2A; open arrow) reflecting membrane resistance of $10.3 \mathrm{M} \Omega$ at this holding potential.

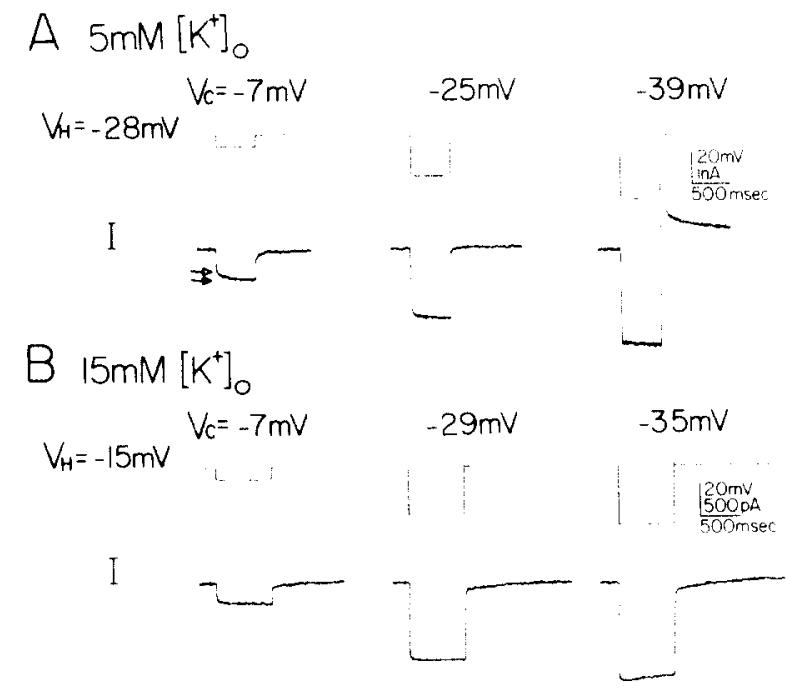

Fig. 2. Hyperpolarization-induced slow potassium-dependent current relaxations. A: voltage-step, current-response pairs from a neuron bathed in TBS containing $5 \mathrm{mM} \mathrm{KCl}$ and $5 \mathrm{mM}$ TEA are shown. $V_{H}$ was $-28 \mathrm{mV}$ and $\mathrm{Vm}-50 \mathrm{mV}$. $\mathrm{V}_{\mathrm{C}} \mathrm{s}$ of $-7 \mathrm{mV},-25 \mathrm{mV}$ and $-39 \mathrm{mV}$ produced slow inward current relaxations of $280 \mathrm{pA}, 250 \mathrm{pA}$ and $75 \mathrm{pA}$, respectively. At command-off, the slow outward current relaxation had two phases. The rapid, large initial outward current at command-off decreased rapidly, suggesting inactivation, and was possibly due to activation of a potassium current similar to A-current [4]. B: voltage-step, current-response pairs from a neuron bathed in TBS containing $15 \mathrm{mM} \mathrm{KCl}$ and $10 \mathrm{mM}$ TEA are shown. $V_{\mathrm{H}}$ was $-15 \mathrm{mV}$ and $\mathrm{Vm}-37 \mathrm{mV}$. For $V_{\mathrm{C}}$ of $-7 \mathrm{mV}$ there was an inward current relaxation of $-80 \mathrm{pA}$ following the initial current. At command-off the initial current was also followed by a slow outward current relaxation of $+100 \mathrm{pA}$. With a moderately large command $\left(\mathrm{V}_{\mathrm{c}}=-29 \mathrm{mV}\right)$, the slow inward current relaxation was less than $-50 \mathrm{pA}$. At command-off a slow outward curent relaxation of $+150 \mathrm{pA}$ was observed. For a larger $V_{C}(-35 \mathrm{mV})$, there was a slow outward current relaxation of $+75 \mathrm{pA}$ at command-on and a slow outward current relaxation of $+150 \mathrm{pA}$ at command-off. 
Over the 500 msec period, the inward current increased (to $950 \mathrm{pA}$ ) yielding an inward current tail of $280 \mathrm{pA}$ (Fig. $2 \mathrm{~A}$; solid arrow). At the end of the $\mathrm{V}_{\mathrm{C}}$, membrane potential was stepped back (to $-28 \mathrm{mV}$ ), and the early current was less (600 pA) than observed at command onset indicating that membrane conductance had decreased during hyperpolarization. Thus, the inward current tail resulted from reducing an outward current present at $-28 \mathrm{mV}$ (also see Fig. 3). Inward current relaxations resulting from small $(-7 \mathrm{mV})$, moderate $(-25 \mathrm{mV})$ and large $(-39 \mathrm{mV})$ negative $V_{C}$ decreased as $V_{C}$ amplitude was increased, suggesting that the inward tail current approached an equilibrium potential (Fig. 2A). Since resting membrane potential in this cell was $-50 \mathrm{mV}$, and the extrapolated reversal potential for current relaxation was $-71 \mathrm{mV}$, these data were consistent with the inward current relaxations being due to the closing of a population of time- and voltage-dependent potassium channels. Often for large $V_{C} s$, the early current observed at command-off was followed by a rapid outward current relaxation (Fig. 2A) which peaked above baseline and rapidly inactivated (see legend to Fig. 2). This additional outward current relaxation frequently obscured the slower relaxation expected for m-current.

To confirm the dependence of the inward current on potassium, neurons were bathed in $15 \mathrm{mM}$ potassium-containing medium to shift $E_{K}$ to more positive potentials, and the current relaxations were examined. Again, small $(-7 \mathrm{mV})$, moderate $(-29 \mathrm{mV})$ and large $(-35 \mathrm{mV})$ negative $V_{C}$ from $V_{H}$ at $-15 \mathrm{mV}(\mathrm{Vm}=-37 \mathrm{mV})$ evoked current relaxations. A small inward current relaxation was seen for a small $\mathrm{V}_{C}(-7 \mathrm{mV})$. However, for a larger $\mathrm{V}_{C}(-35 \mathrm{mV})$ the current relaxation was outward, indicating that its reversal potential $(-47 \mathrm{mV})$ was near $E_{K}$. Thus, increasing the bathing medium potassium concentration shifted the reversal potential of the current relaxation to a less negative potential as predicted for a potassium current. In addition, a slow outward current relaxation was observed (Fig. 2B) at commandoff, as expected if $m$-current channels were activated by depolarization.

We examined the muscarinic sensitivity of current relaxations generated by brief negative commands $\left(\mathrm{V}_{\mathrm{C}}=-20 \mathrm{mV}\right)$ from holding potential $(-25 \mathrm{mV})$ by applying $25 \mu \mathrm{M}$ DL-muscarine from a large tipped glass micropipette (Fig. 3). In control conditions (Fig. $3 \mathrm{~A}_{1}$ ) there was a slow inward current relaxation of $-175 \mathrm{pA}$ during the 500 msec interval (Fig. 3B insert; open arrow) which had a single time constant ( $\tau$ ) of $160 \mathrm{msec}$ (Fig. 3B; filled squares). Application of $25 \mu \mathrm{M}$ muscarine by diffusion from a nearby pipette reduced the amplitude of the inward and outward current relaxations observed at command-on and command-off (Fig. 3 $\mathrm{A}_{2}$ ). Comparison of the inward current relaxation $\tau$ prior to $(\square)$ and following $(\square)$ muscarine application indicated that muscarine decreased the magnitude of the current relaxation without changing $\tau$ (Fig. 3B). The magnitude of the m-current in these cells was small (less than $0.5 \mathrm{nA}$ in most) and, as in frog sympathetic ganglion neurons, it was not blocked by 5 or $10 \mathrm{mM}$ TEA (Fig. 2B; legend).

Thus, it appeared that muscarine-induced inward currents recorded in large multipolar mouse spinal cord neurons in primary dissociated cell culture may be 


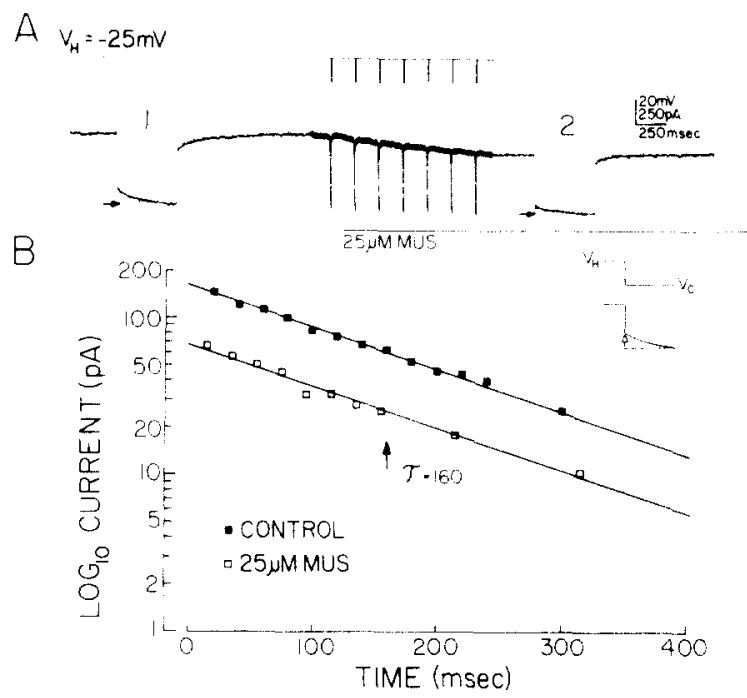

Fig. 3. Muscarine decreased the slow current relaxation without altering its kinetics. A: continuous voltage (upper trace) and current (lower trace) records show expanded time records of current responses to $\mathrm{V}_{\mathrm{C}}$ of $-20 \mathrm{mV}$ (from $\mathrm{V}_{\mathrm{H}}=-25 \mathrm{mV}$ ) in control (1) and in the presence of $25 \mu \mathrm{M}$ muscarine (2). The slow inward current relaxation in control was -- $200 \mathrm{pA}$, and the slow outward current relaxation was $+225 \mathrm{pA}$. Application of $25 \mu \mathrm{M}$ muscarine decreased both slow current relaxations; the inward current relaxation was $-40 \mathrm{pA}$, and the outward current relaxation was $+50 \mathrm{pA}$. Vm was $-45 \mathrm{mV}$. B: the time constant $(\tau=160 \mathrm{msec}$ ) of the inward current relaxation was determined by measuring the current from the steady state curren level (schematic insert at right, open arrow) over the initial $300 \mathrm{msec}$ of the tail current. $\tau \mathrm{s}$ in control (a) and in $25 \mu \mathrm{M}$ muscarine ( ) were the same.

due, at least in part, to agonist reduction of a voltage-dependent $g_{k}$. What might the significance of this small voltage-dependent potassium current be? Concentrations of muscarine $(5-25 \mu \mathrm{M})$ which reduced m-current in spinal cord neurons and resulted in slow inward current responses $(0.1-1.5 \mathrm{nA})$ also produced membrane depolarizations and increased the frequency of action potentials. As pointed out in recent reviews $[9,10]$, neurotransmitter-induced slow potentials have been shown to either potentiate or inhibit more transient synaptic activity. For example, potentiation of fast EPSPs in sympathetic ganglion neurons by muscarinic agonists has been demonstrated suggesting that reduction of m-current may be an effective mechanism for modification of fast synaptic inputs [14]. Thus, reduction of this potassium conductance could enhance postsynaptic sensitivity, both by increasing cell input resistance and by reducing a repolarizing conductance that ordinarily might inhibit sustained firing of action potentials.

We gratefully acknowledge the excellent technical help of Ms. Patricia Szczepanski-Marquardt and secretarial services of Ms. Kathy Lundquist. We also thank Drs. Mary Ann Werz and Susan Barry for their helpful discussions and 


\section{criticisms. This research was supported by NRSA NS 06791 (L.M.N.), RCDA NS} 00401 (R.L.M.) and NSF BNS 81-18762 (R.L.M.).

1 Adams, P.R., Brown, D.A. and Halliwell, J.V., Cholinergic regulation of M-current in hippocampal pyramidal cells, J. Physiol. (Lond.), 317 (1981) 29-30 P.

2 Brown, D.A. and Adams, P.R., Muscarinic suppression of a novel voltage-sensitive $\mathrm{K}^{+}$current in a vertebrate neurone, Nature (Lond.), 283 (1980) 673-676.

3 Brown, D.A. and Constanti, A., Intracellular observations on the effects of muscarinic agonists on rat sympathetic neurones, Brit. J. Pharmacol., 70 (1980) 593-608.

4 Connor, J.D. and Stevens, C.F., Inward and delayed outward membrane currents in isolated neural somata under voltage clamp, J. Physiol. (Lond.), 213 (1971) 1-19.

5 Constanti, A. and Brown, D.A., M-currents in voltage-clamped mammalian sympathetic neurones, Neurosci. Lett., 24 (1981) 289-294.

6 Dodd, J., Dingledine, R. and Kelly, J.S., The excitatory action of acetylcholine on hippocampal neurones of the guinea pig and rat maintained in vitro, Brain Res., 207 (1981) 109-127.

7 Dunn, P.F. and Wilson, W.A., Development of the single microelectrode current and voltage clamp for central nervous system neurons, Electroenceph. clin. Neurophysiol., 43 (1977) 752-756.

8 Freschi, I.E., A qualitative description of the currents seen under voltage clamp of rat sympathetic neurons in culture, Soc. Neurosci. Abstr., 7 (1981) 901.

9 Hartzell, H.C., Mechanisms of slow postsynaptic potentials, Nature (Lond.), 291 (1981) 539-544.

10 Kehoe, J.-S. and Marty, A., Certain slow synaptic responses: their properties and possible underlying mechanisms, Ann. Rev. Biophys. Bioengng., 9 (1980) 437-465.

11 Krnjevic, K., Pumain, R. and Renaud, L., The mechanism of excitation by acetylcholine in the cerebral cortex, J. Physiol. (Lond.), 215 (1971) 247-268.

12 Nowak, L.M. and Macdonald, R.L., DL-Muscarine decreases a potassium conductance to depolarize mammalian spinal cord neurons in cell culture, Soc. Neurosci. Abstr., 7 (1981) 725.

13 Ransom, B.R., Neale, E., Henkart, M., Bullock, P.N. and Nelson, P.G., Mouse spinal cord in cell culture. I. Morphology and intrinsic neuronal electrophysiologic properties, J. Neurophysiol., 40 (1977) 1132-1150.

14 Schulman, J.A. and Weight, F.F., Synaptic transmission: long-lasting potentiation by a postsynaptic mechanism, Science, 194 (1976) 1437-1439.

15 Weight, F.F. and Votava, J., Slow synaptic excitation in sympathetic ganglion cells: evidence for synaptic inactivation of potassium conductance, Science, 170 (1970) 755-758.

16 Zieglgänsberger, W. and Reiter, C., A cholinergic mechanism in the spinal cord of cats, Neuropharmacology, 13 (1974) 519-527. 